\title{
Caracterização Qualitativa do Bem-Estar Subjetivo de Crianças e Adolescentes em Situação de Rua
}

\author{
Rebeca Fernandes Ferreira Lima ${ }^{1}$ \\ Normanda Araujo de Morais \\ Programa de Pós-Graduação em Psicologia da Universidade de Fortaleza, \\ Fortaleza, CE, Brasil
}

\section{Resumo}

Trata-se de estudo de casos múltiplos com objetivo de investigar qualitativamente o bem-estar subjetivo de crianças e adolescentes em situação de rua. Participaram 6 adolescentes de Fortaleza (10-17 anos), todos do sexo masculino. Destes, três viviam em instituição de acolhimento, dois em serviço aberto e um na rua. Utilizou-se entrevista estruturada, figuras representativas dos contextos (escola, família, rua, amigos e instituição) e diário de campo para contemplar os aspectos de satisfação de vida, afetos positivos e negativos. A análise de conteúdo permitiu identificar uma avaliação positiva da satisfação de vida pela maioria dos adolescentes. Eles tenderam a relacioná-la à rede de apoio, projetos futuros e estar vivendo numa situação melhor do que vivia antes de virem para a rua. Atribuiu-se os afetos positivos ao relacionamento com os pares, à presença dos familiares, apoio das instituições para familiares e envolvimento em atividades lúdicas e de lazer. Já os afetos negativos relacionaram-se aos conflitos e brigas (com amigos, familiares e profissionais das instituições), preconceitos da sociedade, punições por desobedecer regras, realização de atividades domésticas e violência física e sexual. A rua e a família foram os contextos mais associados aos afetos negativos quando comparados à instituição, à escola e aos amigos. Porém, os afetos positivos não estiveram excluídos da rua e da família. Enfatiza-se a importância de estudos acerca dos processos positivos, os quais propõem uma leitura mais abrangente do desenvolvimento humano em contextos de vulnerabilidade e que não estejam baseados exclusivamente no levantamento de indicadores de risco vivenciados por essas populações.

Palavras-chave: Satisfação de vida, afeto positivo, afeto negativo, adolescentes, situação de rua.

\section{Qualitative Characterization of Subjective Well-Being of Street Youth}

\begin{abstract}
This multiple case study aimed to investigate qualitatively the subjective well-being of children and adolescents that live on streets. Six male adolescents from Fortaleza city (10-17 years old) participated. Three were living in the foster care institution, two on temporary shelter and one on the streets. Structured interviews, pictures representing different contexts (school, family, streets, friends and institution), and field notes were used to contemplate the aspects of life satisfaction, positive and negative affects. Content analysis allowed the identification of a positive evaluation of life satisfaction by most adolescents. They tended to relate it to their support network, to future projects and by comparing their
\end{abstract}

Endereço para correspondência: Rua João Paulino Barros Leal, 2519, Fortaleza, CE, Brasil 60120-060. Fone: (85) 3247-4016 / (85) 88042-462. E-mail: rebecafflima@gmail.com e normandaaraujo@gmail.com Apoio financeiro: Trabalho realizado com apoio da Jacobs Fundation e Edital Universal do Conselho Nacional de Desenvolvimento Científico e Tecnológico (CNPq, 2011). 
improved present situation to the time spent on the streets. Positive affects were related to relationships with partners, presence of family, support from institutions to family and involvement in recreational and leisure activities. Whereas negative affects were related to conflicts and quarrels (with friends, family and professional institutions), prejudices of society, punishment for disobeying rules, performing household activities and physical and sexual violence. The streets and family were the most associated with negative affects compared to the institution, school and friends. However, positive affects were not excluded from the streets and family. It can be emphasized the importance of studies related to the positive processes that propose a more comprehensive reading of the human development in contexts of vulnerability and that are not based solely on the survey of risk indicators experienced by these populations.

Keywords: Life satisfaction, positive affect, negative affect, adolescents, street situation.

\section{Caracterización Cualitativa de Bienestar Subjetivo de Niños en Situación de Calle}

\section{Resumen}

Es un estudio de casos múltiple para investigar cualitativamente el bienestar subjetivo de los niños y adolescentes que viven en la calle. Participaron 6 adolescentes de Fortaleza (10-17 años), todos de sexo masculino. Tres vivían en institución de acogida, dos en servicio abierto y uno en la calle. Utilizamos entrevistas estructuradas, figuras representativas de contextos (escuela, familia, calle, amigos y institución) y diario de campo para incluir asuntos de satisfacción con la vida y afectos. Análisis de contenido permitió identificar un balance positivo acerca de la satisfacción con la vida en la mayoría de los adolescentes. Tendieron a relacionarla con red de apoyo, proyectos futuros y vivir en una mejor situación que antes de su salida a la calle. Atribuyeron afectos positivos a relación con pares, presencia de miembros de la familia, apoyo de las instituciones para la familia y participación en actividades recreativas y de ocio. Relacionaron emociones negativas con conflictos y peleas (con amigos, familia y instituciones profesionales), discriminación por parte de la sociedad, castigos por desobedecer reglas, realización de tareas domésticas y violencia física y sexual. La calle y familia fueron contextos que más se asociaron con efectos negativos en comparación con institución, escuela y amigos. Sin embargo, afectos positivos no fueron excluidos de la calle y familia. Hacemos hincapié en la importancia de estudios sobre procesos positivos, que ofrecen una lectura más amplia del desarrollo humano en contextos de vulnerabilidad y no basadas exclusivamente en un sondeo de los factores de riesgo experimentados por estas poblaciones.

Palabras clave: Satisfacción con la vida, afecto positivo, afecto negativo, adolescentes, situación de calle.

O bem-estar subjetivo é um construto multidimensional constituído por avaliações subjetivas dos indivíduos acerca de suas vidas, decorrentes tanto de experiências circunstanciais quanto julgamentos cognitivos. Os sentimentos agradáveis e desagradáveis resultantes de vivências imediatas são denominados afetos positivos e negativos, respectivamente. Junto aos afetos, o juízo conceitual de dimensões específicas (família, por exemplo) ou da vida em sua totalidade é definido como satisfação de vida. Este domínio é avaliado através de um padrão social escolhido pelo indivíduo ou por comparações com situações passadas de sua própria vida. Designa-se, portanto, os afetos positivos, os afetos negativos e a satisfação de vida como componentes do bem-estar subjetivo (Diener, Suh, Lucas, \& Smith, 1999; Snyder \& Lopez, 2009).

Alguns estudos defendem que o equilíbrio entre os afetos positivos e negativos são indicadores de felicidade. Porém, evidencia-se que os afetos positivos e negativos são dimensões independentes. Isto é, para caracterizar o bem-estar não é necessário a ausência de afetos negativos. 
Além disso, a satisfação de vida pode funcionar como reguladora das emoções, sejam positivas ou negativas, aumentando ou diminuindo cada uma delas em acordo com a dimensão cognitiva da pessoa. Destaca-se ainda que o bem-estar é um construto multifacetado, ou seja, não pode ser descrito pela avaliação isolada de seus componentes. Salienta-se, destarte, a análise associada de seus elementos afetivos e cognitivos (Diener et al., 1999; Giacomoni, 2004; Snyder \& Lopez, 2009).

Inicialmente, as teorias sobre o bem-estar subjetivo, denominadas de bottom-up, buscaram identificar variáveis externas como fatores determinantes. Porém, verificou-se que nível socioeconômico, gênero, raça, etc. não designam expressiva influência sobre o bem-estar, divergindo em importância nas diferentes culturas. À vista disso, pesquisas mais atuais sobre o bem-estar subjetivo, nomeadas de top-down, apontam para uma predisposição que as pessoas dispõem para interpretar as situações de vida, de modo tanto positivo quanto negativo, e essa disposição influencia a avaliação de vida (Diener, 2012; Diener et al., 1999; Giacomoni, 2004).

Nessa perspectiva, desloca-se o sentido de felicidade para a percepção subjetiva das pessoas. De tal sorte que, independente de classe econômica, gênero, etc., pode-se defender que as pessoas são felizes se assim se perceberem. Assim, desconstroem-se ideais sociais sobre felicidade, indicando a avaliação individual como definidora de bem-estar. Pesquisas creditam que jovens em situação de rua descrevem-se com altos níveis de afetos positivos e satisfação de vida e mesmo quando comparados a adolescentes que vivem com suas famílias apresentam maiores níveis de eventos adversos de vida como também de afetos positivos e satisfação de vida (Morais, 2009; Morais, Koller, \& Raffaelli, 2010; Poletto, 2011; Siqueira \& Dell'Aglio, 2010).

Enfatiza-se a importância de pesquisas pautadas na complexidade que envolve os jovens em situação de rua, demonstrando que estes não estão limitados a aspectos negativos ou mesmo ao determinismo social e demais fatores externos. Ampliando-se a atenção sobre os aspectos positivos, surge um campo de estudo que pode atuar (mais ativamente) no subsídio a políticas públicas de garantia dos direitos humanos. Nesse sentido, a investigação sobre o bem-estar subjetivo é coerente com a concepção do desenvolvimento no contexto, visto que em ambas as construções teóricas privilegia-se a função ativa das pessoas sobre suas experiências de vida.

Em acordo com a Abordagem Bioecológica do Desenvolvimento Humano (ABDH), o indivíduo é apreendido em sua complexidade sistêmica (Bronfenbrenner, 1979/1996). Para a compreensão dos fenômenos em torno do desenvolvimento humano amplia-se o olhar para os processos biopsicológicos da pessoa em interação com o meio. Assim, o indivíduo é visto como possuidor de características pessoais (intrínsecas e adquiridas) e participante ativo nas relações com as pessoas e os ambientes, seja a família, a instituição de acolhimento, a rua ou mesmo o contexto cultural ampliado da sociedade em que está inserido. Dessa forma, possibilita-se a percepção de fatores que podem ser tanto prejudiciais como protetivos ao desenvolvimento nos variados contextos em que os jovens em situação de rua estabelecem seus vínculos sociais e afetivos.

Outro destaque da abordagem bioecológica em pesquisas com jovens em situação de rua refere-se à sua concepção teórica que privilegia a percepção da pessoa sobre o seu contexto de desenvolvimento em detrimento de uma realidade objetiva. Esta característica influencia o foco dado aos estudos, pois se aproxima ao enfoque sobre os aspectos saudáveis dos indivíduos (Morais, 2009). Esta qualidade acentua-se nos estudos da Psicologia Positiva, pois se ampliam as possibilidades de compreensão acerca do desenvolvimento humano que ocorre em interação com contextos em que as adversidades tanto quanto a diversidade se faz presente. Tal fato decorre da percepção de que jovens que vivenciam cotidianamente eventos adversos, que os caracterizam como uma população em situação de risco pessoal e social continua a se desenvolver; podendo demonstrar (em maior ou menor nível) características desenvolvimentais negativas (dificuldades escolares, uso de drogas, etc.), mas também características positivas (autoestima, autoeficácia, bem-estar subjetivo etc.). 
Nos primeiros estudos sobre a abordagem bioecológica, esta esteve centrada nas influências do contexto sobre o desenvolvimento. Em sua reformulação, a $\mathrm{ABDH}$ propõe a compreensão do desenvolvimento humano por meio de quatro núcleos inter-relacionados: Pessoa, Processo, Contexto e Tempo (PPCT), possibilitando uma apreensão complexa e integrada sobre a dinâmica do processo de desenvolvimento, envolvendo as características dos indivíduos em interação com as pessoas, os objetos e símbolos do contexto, ao longo do tempo (Bronfenbrenner, 2011).

Nota-se que compreender o bem-estar subjetivo a partir de uma perspectiva qualitativa, que privilegia a percepção dos participantes em seu ambiente natural e através de relatos sobre suas experiências de vida acrescenta um novo olhar ao construto investigado. A partir de análises qualitativas pode-se abordar o bem-estar subjetivo em sua complexidade, a fim de um conhecimento substancial sobre o bem-estar subjetivo de jovens em situação de rua.

Este estudo teve como objetivo compreender o significado de bem-estar subjetivo para crianças e adolescentes em situação de rua a partir da realização de estudos de casos múltiplos. Especificamente, buscou-se: descrever a satisfação de vida e quais fatores estavam relacionados a esta; investigar quais situações estavam relacionadas, na percepção das crianças e adolescentes em situação de rua, aos afetos positivos e negativos; e, identificar quais contextos (família, escola, instituições, amigos e rua) estavam relacionados aos afetos positivos e negativos.

\section{Método}

Tratou-se de um estudo descritivo, transversal e delineamento de estudo de casos múltiplos. Esta estratégia de pesquisa, de acordo com Yin (2010), consiste no relato dos casos escolhidos sem descrevê-los individualmente com profundidade, mas utilizando-os como ilustrações na discussão dos tópicos de investigação. Assim, a análise cruzada das situações e comportamentos dos casos múltiplos serve para retratar as categorias, eixos ou perguntas de análise.

\section{Participantes}

Participaram da pesquisa seis adolescentes, do sexo masculino, com idades que variaram entre 10 a 17 anos $(M=14$ anos; $D P=3,03)$. Três deles foram entrevistados em uma instituição de acolhimento, dois em um serviço aberto e um na rua da cidade de Fortaleza - CE. Cada um desses contextos é melhor descrito na seção de procedimentos de coleta de dados.

\section{Instrumentos}

Utilizou-se uma entrevista estruturada composta de três tópicos que abordam dados sociodemográficos, percepções sobre satisfação de vida e percepções sobre afetos positivos e negativos. Esta entrevista foi elaborada especialmente para este estudo pelas autoras do mesmo.

O tópico de percepções sobre satisfação de vida baseou-se na Escala de Satisfação de Vida (Diener, Emmons, Larsen, \& Griffin, 1985; Koller \& Hutz, 1996) composta por 5 itens (1discordo fortemente a 5 - concordo fortemente). Desta adaptou-se uma entrevista na qual foram abordadas questões, tais como: "você está satisfeito com sua vida?", "você está próximo do ideal?", "quais diferenças existem entre o seu ideal e sua vida de hoje?". As perguntas foram baseadas na técnica tridimensional utilizada no Family System Test (FAST; Gehring, 1993) que avalia a percepção do indivíduo sobre a coesão e hierarquia na família em situações típicas, ideais e conflituosas. Para motivar a avaliação da satisfação de vida pelos participantes no que tange seus ideais, solicitou-se ao participante um desenho de sua "vida ideal".

Os afetos foram acessados a partir das questões: "como você se sente a maior parte do tempo?" e "conte-me uma situação que aconteceu nos últimos dias em que você se sentiu...", seguida de itens contendo os afetos positivos (divertido e animado, por exemplo) e negativos (incomodado e humilhado, por exemplo). A escolha desses afetos fundamentou-se na Positive and Negative Affect Scale for Children (PANAS-C8; Damásio, Pacico, Poletto, \& Koller, 2013), originalmente desenvolvida por Watson, Clark e Tellegen (1988) e adaptada no Brasil por Giacomoni e Hutz (2006). Esta versão original é 
composta por 34 itens e foi reduzida para 8 itens por Damásio et al. (2013), encontrando adequadas propriedades psicométricas. A PANAS-C8 contém uma estrutura bifatorial com 4 itens por fator, a fim de mensurar os afetos positivos e negativos. São esses: divertido, contente, animado, incomodado, humilhado, magoado, irritado e alegre.

A fim de verificar os contextos (família, escola, instituições, amigos e rua) que estão relacionados aos afetos positivos e negativos, foram utilizadas figuras representativas dos contextos que podem ser acessadas no estudo de Lima (2014). A partir destas, os participantes identificaram quais afetos estavam presentes nos determinados contextos. Para cada afeto foram produzidas cinco fichas iguais que nomeavam esses afetos (total de 40 fichas), tendo em vista a possibilidade dos participantes sentirem cada um dos afetos em todos os diferentes contextos ou apenas naqueles selecionados por eles. A partir desse material exposto, foi solicitado aos adolescentes que escolhessem, primeiramente, um afeto e colocasse-o nos contextos nos quais ele sentia aquele afeto. Assim procedeu-se com cada um dos oito afetos.

Além disso, utilizou-se o diário de campo no qual foram feitos os registros sistemáticos dos dados obtidos durante a Inserção Ecológica (descrita nos procedimentos de coleta de dados). Nele foram anotadas descrições, trechos de fala dos participantes, impressões e sentimentos da pesquisadora, desde o seu primeiro contato com as instituições e as crianças e adolescentes até o encerramento da coleta de dados (Morais, 2009).

\section{Procedimento de Coleta de Dados}

Este estudo foi parte de um projeto de pesquisa mais abrangente, intitulado: "O impacto da vida na rua em adolescentes: Um estudo longitudinal sobre risco e proteção", desenvolvido em três capitais brasileiras: Fortaleza, Porto Alegre e Salvador. Como também constituiu parte da Dissertação de mestrado da primeira autora, a qual buscou investigar quantitativa e qualitativamente o bem-estar subjetivo de crianças/adolescentes em situação de rua. Na etapa quantitativa, dados das três cidades foram utilizados. No es- tudo qualitativo, porém, uma vez que as autoras residiam em Fortaleza, foram usados dados de participantes apenas dessa cidade.

Os participantes foram recrutados em espaços selecionados por conveniência, visto o vínculo estabelecido entre a pesquisadora e o contexto natural dos participantes. Buscou-se também contemplar diferentes espaços de coleta de dados (acolhimento institucional, serviço aberto e rua). A partir da seleção dos locais, foi realizado um sorteio de seis jovens entre os 45 que participaram da pesquisa em Fortaleza. Posteriormente, as seis crianças/adolescentes sorteados foram convidados a participar desse estudo e, mediante assentimento, realizaram-se as entrevistas estruturadas e individuais nos contextos naturais dos participantes. Cada entrevista ocorreu em um encontro com duração média de 45 minutos.

$\mathrm{O}$ acolhimento institucional é oferecido em uma unidade institucional semelhante a uma residência. Nesta, aconselha-se que os educadores sociais trabalhem em horários fixos para garantir estabilidade das tarefas do cotidiano. Também é garantido aos jovens com vínculos de parentesco que possam residir na mesma instituição. De forma diferente, os serviços abertos funcionam em caráter provisório. Os jovens possuem a liberdade de transitar por esses espaços, utilizando-os, por exemplo, por três dias ou uma semana e ao deixar esses locais, podem retornar quando desejarem. No entanto, havendo o descumprimento de normas e regras, os adolescentes ficam privados da utilização desses serviços por 72 horas. As ruas também foram espaços de coleta de dados ao passo que alguns educadores sociais realizavam abordagem nas ruas e, portanto, facilitaram a vinculação entre os pesquisadores e a população de adolescentes que estavam nas ruas.

A inserção ecológica privilegiou a inserção do pesquisador no ambiente de pesquisa, a fim de favorecer a proximidade com o seu objeto de estudo e, assim, responder às questões de pesquisa (Cecconello \& Koller, 2003; Eschiletti-Prati, Paula Couto, Moura, Poletto, \& Koller, 2008; Morais, Koller, \& Raffaelli, no prelo). Visando a vinculação entre o pesquisador, os adolescentes e o contexto de pesquisa, a equipe de pesquisa 
esteve durante seis meses frequentando de duas a três vezes por semana os locais selecionados para o recrutamento dos participantes.

\section{Procedimentos de Análise de Dados}

Os dados coletados nas entrevistas foram transcritos e analisados através do levantamento de categorias temáticas a posteriori, de acordo com a Análise de Conteúdo (Bardin, 1977/1979). Para a autora, a Análise de Conteúdo é composta por três fases, sendo: (a) a pré-análise; (b) a exploração do material; e, (c) o tratamento dos resultados e interpretação. A primeira consistiu na organização das temáticas através de leitura flutuante, hipóteses, formulação de hipóteses, objetivos e elaboração de indicadores. Na segun$\mathrm{da}$, os dados foram codificados a partir de unidades de registro em acordo com o significado presente no relato dos participantes. Na terceira foi realizada a categorização das temáticas a partir de classificações dos dados em acordo com suas semelhanças e por diferenciação. Portanto, trabalharam-se as temáticas apresentadas no material do texto, estabelecendo categorias para sua interpretação.

\section{Procedimentos Éticos}

A presente pesquisa recebeu aprovação do Comitê de Ética da Universidade de Fortaleza (Protocolo 2011023) em Dezembro de 2011. Os procedimentos de consentimento utilizados nesta pesquisa obedeceram aos Critérios da Ética na Pesquisa com Seres Humanos, pautados na Resolução 196/1996 do Conselho Nacional de Saúde (vigente à época de aprovação do referido projeto), ao Estatuto da Criança e do Adolescente (1990) e às diretrizes do Conselho Federal de Psicologia (Resolução n. 016/2000).

A população-alvo desta pesquisa se caracteriza por ter vínculos familiares fragilizados e/ou rompidos, seja por relações conflituosas ou abusos. Assim, o consentimento parental foi desconsiderado e o projeto foi apresentado ao Ministério Público que concedeu sua autorização. Além disto, foram realizadas reuniões de apresentação do projeto e assinatura do Termo de Concordância para cada instituição em que ocorreu a inserção da equipe de pesquisa. Por fim, buscou-se o assentimento de cada adolescente recrutado para participar da pesquisa. Para estes, explicou-se o objetivo da pesquisa, a natureza voluntária do estudo, a não existência de recompensa material pela participação e a autonomia do adolescente em participar ou recusar, ou mesmo desistir ao longo do processo.

\section{Resultados e Discussão}

Os resultados e análise dos dados serão apresentados em três grandes blocos, a saber: (a) Descrição dos Participantes; (b) Satisfação de Vida; e (c) Situações Relacionadas aos Afetos Positivos e Negativos. A satisfação de vida foi avaliada através da percepção sobre as condições de vida atual e de uma "vida ideal", apontando as diferenças existentes e os fatores que contribuíram para uma avaliação geral da satisfação de vida. Já os afetos positivos e negativos foram investigados a partir de situações em que os participantes sentiam cada afeto estudado.

\section{Descrição dos Participantes}

Adolescente 1 (A1). A1 tinha 10 anos e começou a ir para a rua aos 8 anos de idade. Antes de sair de casa, morava com sua mãe e dois irmãos. Seus pais eram envolvidos com o tráfico de drogas e quando A1 tinha 4 anos de idade seu pai foi assassinado por um traficante. Sua ida para a rua foi motivada pela violência física e emocional que vivenciava na família. Ele justificou as agressões sofridas por ser "danado" e gostar de ir brincar na rua. Na rua, dormia pelas calçadas enrolando-se com papelões e conseguia dinheiro para alimentar-se pedindo e furtando. Através da busca ativa de educadores sociais ele foi encaminhado para a instituição de acolhimento na qual estava morando e onde foi entrevistado. Nesta, estudava e relatou com entusiasmo a visita que recebeu de sua mãe que estava grávida e acompanhada por seu irmão caçula. A1 disse sentir saudade de sua mãe e queria ir para casa nas férias escolares, mas não seria possível, pois sua mãe continuava envolvida com o tráfico de drogas e morando nas ruas.

Adolescente 2 (A2). A2 tinha 12 anos e começou a ir para a rua aos 9 anos de idade. $\mathrm{Na}$ 
rua andava pela cidade, dormia nas calçadas e cheirava solvente. Para conseguir dinheiro e comida pedia e furtava. Antes de ir para a rua, o adolescente morava com seu pai e madrasta. $\mathrm{Na}$ família, sofria violência física por parte de seu pai. Ao sair de casa, ele foi acolhido por diversas instituições, mas evadia para ficar na rua. Ele estudava na instituição de acolhimento em que estava morando no momento da entrevista e não tinha contato com a família, que mora em outra cidade. Ele relatou que não gostava de estudar, mas que se sente bem em continuar na instituição, estar estudando e disse que pretende trabalhar para ajudar a família.

Adolescente 3 (A3). A3 tinha 12 anos e vivia desde os 8 anos de idade na rua. Ao sair de casa estava morando com seu pai, mãe e cinco irmãos. A relação familiar era conflituosa, o adolescente sofria violência emocional e física na família. $\mathrm{Na}$ rua, ele usava álcool, maconha e cocaína na companhia de um primo. Para conseguir dinheiro, ele furtava e vendia drogas. Nesse período estava matriculado na escola, mas não tinha uma boa frequência. Em alguns dias dormia em casa, em outros na casa do primo ou permanecia na rua, dormindo nas calçadas. Sua mãe buscou a instituição de acolhimento na qual o adolescente estava morando no momento da entrevista. Ele mantinha contato esporádico apenas com seu primo e sentia-se bem por estar estudando. Mas, demonstrou insatisfação quando relatou que sofria violência física de um educador social nessa instituição.

Adolescente 4 (A4). A4 tinha 16 anos e começou a ir para a rua aos 13 anos de idade. Antes da ida para a rua, o adolescente morava com seu pai, mãe e quatro irmãos. A relação familiar era conflituosa e quando seus pais se separaram, ele começou a ir para a rua para pedir dinheiro e comida, visto a dificuldade financeira da família. Também roubava dinheiro dos caixas de ônibus e cheirava cola. Através da busca ativa de educadores sociais, ele foi encaminhado para uma instituição de acolhimento, na qual se sentiu satisfeito tendo a oportunidade de estudar e trabalhar. Além dessa, morou em três outras instituições, mas evadia por discussões com educadores sociais. No momento da pesquisa, o adolescente alternava a rua com um serviço aberto e tinha contato esporádico com uma tia por telefone.

Adolescente 5 (A5). A5 tinha 17 anos e começou a ir para a rua aos 9 anos de idade. Antes da ida para a rua, o adolescente morava com sua mãe, padrasto e dois irmãos. A dificuldade financeira da família e o uso de drogas motivou a ida do adolescente para a rua. Na rua, o adolescente consumia drogas, furtava e pedia dinheiro e comida para a população. Ele andava pelos terminais de ônibus e pela praia, dormindo pelas calçadas. $\mathrm{O}$ adolescente não frequentava a sua comunidade nem tinha contato com seus familiares, pois estava ameaçado de morte por traficantes nessa localidade. Durante sua vida morou em três instituições de acolhimento e foi internado para tratamento de dependência química. No momento da pesquisa, ele estava num serviço aberto, usava maconha e cigarro, participava de um projeto socioeducativo e trabalhava numa rede de lanchonetes. $\mathrm{O}$ adolescente mostrou-se preocupado com seu futuro, pois não poderia retornar para casa de sua família ao completar a maioridade.

Adolescente 6 (A6). A6 tinha 17 anos, aos 11 anos começou a ir para a rua e estava morando na rua no momento da entrevista. Antes da ida para a rua, o adolescente morava com a mãe e um irmão. A relação com sua mãe era conflituosa, ela ameaçava expulsá-lo de casa, mas ele dizia não se importar, pois estava acostumado a dormir nas ruas e na rodoviária. Na rua, o adolescente usava crack, álcool e maconha e para conseguir dinheiro e comida furtava e pedia para a população. Ele foi encaminhado para uma instituição de acolhimento, mas evadiu para usar drogas. No momento da pesquisa, ele não estudava nem trabalhava e gostava da rua para aproveitar as festas que frequentava à noite com seus amigos e continuava usando drogas com exceção do crack. $\mathrm{O}$ adolescente estava pensando em morar com seu pai para trabalhar com ele, mas ainda não havia ido por sofrer violência emocional de seu pai.

\section{Satisfação de Vida}

A satisfação de vida foi avaliada positivamente pela maioria dos participantes. Eles ten- 
deram a relacioná-la à rede de apoio, projetos futuros e estar vivendo numa situação melhor do que vivia antes de virem para a rua. Apenas um adolescente disse não estar satisfeito com sua vida. Ele relatou: "eu não tenho apoio da minha família" (A5, 17 anos). Assim, verificaram-se três eixos temáticos que se referem às descrições dos adolescentes sobre a satisfação de vida apresentadas na Tabela 1.

Tabela 1

Avaliação e Descrição dos Participantes Acerca da Satisfação de Vida a partir de Eixos Temáticos

\begin{tabular}{|c|c|c|}
\hline $\begin{array}{l}\text { Avaliação quanto } \\
\text { à Satisfação de Vida }\end{array}$ & Eixo temático & Descrições dos participantes \\
\hline Negativa & Ausência de apoio familiar & "Eu não tenho apoio da minha família" (A5, 17 anos). \\
\hline \multirow[t]{2}{*}{ Positiva } & $\begin{array}{c}\text { Condições atuais de vida/ } \\
\text { Ter saído da rua }\end{array}$ & $\begin{array}{l}\text { "Antigamente eu era de rua... não tinha o que fazer. Ai } \\
\text { agora eu tô satisfeito de tá aqui [instituição]. Porque eu } \\
\text { tenho um bocado de coisa pra fazer. Estuda, brinca, joga } \\
\text { bola, escuta funk" (A3, } 12 \text { anos). }\end{array}$ \\
\hline & Aspirações futuras & $\begin{array}{l}\text { "Sim. Muito. Porque assim... tô indo atrás do que eu que- } \\
\text { ro e tô gostando do que eu tenho e do que eu vou con- } \\
\text { seguir ainda... arrumar trabalho o mais rápido possível } \\
\text { e juntar dinheiro pra conseguir comprar ou alugar uma } \\
\text { casa, um kitnet pra mim ficar morando" (A } 4,16 \text { anos). }\end{array}$ \\
\hline
\end{tabular}

Num estudo de revisão de literatura sobre o bem-estar subjetivo de jovens em situação de rua na América Latina (Raffaelli, Morais, \& Koller, 2013), verificou-se que a rua constitui-se como uma alternativa concreta de sobrevivência. Ou seja, muitas vezes, os adolescentes saem de suas casas pelo contexto familiar ser perpassado por conflitos, violência e pobreza. Nesse sentido, essa população tende a avaliar positivamente suas vidas nas ruas quando comparado a situações anteriores de vulnerabilidade e risco.

Quando questionados sobre uma "vida ideal" e solicitados a desenhá-la, a totalidade do grupo relacionou a vida idealizada com a presença dos familiares, seja da família de origem ou constituída e a estarem em casa. Salienta-se que, independente da configuração e proximidade familiar, os participantes remeteram-se à família nuclear (mãe, pai e filho). Tal como se observa no relato a seguir: "Aqui é minha casa, meu pai, minha mãe e aqui nós três se divertindo, tomando banho de chuva" (A2, 12 anos).

O imaginário social é perpassado pela noção de que a definição de família se restringe ou se delimita exclusivamente pelos laços consan- guíneos e/ou ao espaço do domicílio (Gomes \& Pereira, 2005). Numa pesquisa que investigou a percepção de jovens em situação de rua sobre suas famílias foram verificados sentimentos de afeto e aceitação alternados por histórias de maus tratos e rejeição dos familiares. Constatou-se que a percepção sobre a família oscila na ambiguidade entre uma família pensada (relacionada ao ideal social da família nuclear) e aquela vivida no cotidiano (Yunes, Arrieche, Tavares, \& Faria, 2001).

A satisfação de vida relacionada à família também foi verificada na pergunta que se seguiu sobre o que os jovens fariam de diferente em suas vidas. Apenas um participante (A6, 17 anos) disse que não faria nada de diferente em sua vida. Porém, sua associação também esteve relacionada à família, como se pode observar: "Mudaria não. Minha mãe tá viva ainda. Meu pai, meu irmão". Estar com a família e não ter saído de casa para a rua foram respostas associadas a atitudes no passado que poderiam modificar as condições atuais de vida, tal como diz o participante: "Se eu não tivesse saído de casa" (A2, 12 anos). 
Estudar, trabalhar e não usar drogas estiveram relacionados à satisfação de vida quando questionado aos participantes se eles estão conseguindo as coisas importantes que querem na vida. Como diz o participante: "Macho, só era ruim mesmo com o diabo dessa pedra [crack] aí. Mas, taí, num consegui sair também?!" (A6, 17 anos).

Verifica-se que os resultados deste estudo no que se refere à satisfação de vida apresentam, em maioria, participantes que se avaliam satisfeitos com suas vidas. A rede de apoio (família e instituição), as aspirações futuras e condições atuais de vida melhores que situações passadas na rua contribuíram para a percepção positiva dos participantes acerca de suas vidas. Em contrapartida, o fracasso escolar, o uso de drogas, a ausência do apoio familiar e a ida para a rua foram associados a uma avaliação negativa dos participantes quanto à satisfação de vida.

Esses resultados corroboram a teoria de que a situação de rua não se configura como condição ideal para o desenvolvimento saudável das crianças e adolescentes. No entanto, constitui-se como uma possibilidade de manutenção de um funcionamento positivo, visto que a situação anterior de vida apresentava vulnerabilidade e risco potencialmente prejudiciais (Raffaelli et al., 2013). Enfatiza-se que apesar da história de vida dos participantes serem perpassadas por fatores de risco à sua saúde biopsicossocial, eles avaliaram suas experiências de vida percebendo-as como positivas. Seja pela condição atual de vida ou por aspirações futuras, a satisfação esteve presente em suas falas.

Observa-se que avaliações positivas sobre a vida não significa ausência de eventos adversos de vida, os quais tendem a ser avaliados a partir de afetos negativos, como apresenta estudos sobre o bem-estar subjetivo com adolescentes em vulnerabilidade social (Morais, 2009; Morais, Koller, et al., 2010; Poletto, 2011). Porém, além disso, os afetos positivos e a satisfação de vida colaboram para a percepção de que as crianças e adolescentes em situação de rua continuam a se desenvolver.

\section{Situações Relacionadas aos Afetos Positivos e Negativos}

Os relatos em resposta aos questionamentos sobre situações e contextos relacionados à dimensão afetiva do bem-estar subjetivo foram analisados e categorizados por afetos positivos e negativos conforme se pode verificar na Tabela 2.

Assim como verificado na literatura, os afetos positivos e negativos dizem respeito a avaliações sobre experiências imediatas agradáveis ou desagradáveis, respectivamente. Portanto, são compreendidos numa perspectiva situacional, em que as avaliações sobre as experiências dos indivíduos variam em acordo com as diferentes demandas circunstanciais (Snyder \& Lopez, 2009). Isto pode ser observado no relato dos participantes que se reportaram a eventos recentes vivenciados em seu cotidiano para descreverem os afetos estudados. Eventos festivos, atividades corriqueiras como jogar, brincar, estudar, trabalhar, realizar atividades domésticas e se relacionar com os amigos são exemplos de acontecimentos atuais experienciados pelos participantes relacionados aos afetos positivos e negativos.

A noção de que o bem-estar subjetivo é descrito a partir de percepções individuais sobre a própria vida (Diener, 2012) é corroborada nesse estudo. As falas dos participantes, em resposta às situações ocorridas que remetiam a cada afeto investigado corresponderam a avaliações subjetivas de experiências pessoais. Isso pode ser verificado, por exemplo, quando foi solicitado aos participantes que identificassem em quais contextos (família, escola, etc.) sentiam os afetos investigados. As respostas variaram entre eles, na medida em que cada um se remeteu à sua história de vida e de como avalia as experiências vividas para apresentar quais contextos sentiam cada afeto. Dessa forma, existiram aqueles em que os afetos positivos predominaram sobre os afetos negativos no contexto da instituição, como também se obteve a resposta de um participante que avaliou negativamente a instituição atual, comparando-a com uma antiga em que ele dizia se sentir em casa.

Em ambas as questões ("Conte-me uma situação que aconteceu nos últimos dias em que 
Tabela 2

Categorias Referentes às Situações, Pessoas e Contextos Relacionadas aos Afetos Positivos e Negativos

\begin{tabular}{|c|c|c|}
\hline Afetos & Eixo temático & Descrição dos participantes \\
\hline \multicolumn{3}{|l|}{$\begin{array}{l}\text { Afeto } \\
\text { Positivo }\end{array}$} \\
\hline & $\begin{array}{l}\text { Trabalhar, estudar } \\
\text { e participar } \\
\text { de oficinas } \\
\text { socioeducativas }\end{array}$ & $\begin{array}{l}\text { "O trabalho, tia. É massa. É massa, má, o cara trabalhar. Agora tem que } \\
\text { tá com tempo. Show de bola. Tá ganhando dinheiro. De vez enquanto eu } \\
\text { fico com uma menina por lá no shopping... tem vezes que eu vou merendar } \\
\text { lá, espero dar minha hora de ir embora... fico por lá. Show de bola" (A5, } \\
17 \text { anos). }\end{array}$ \\
\hline & $\begin{array}{l}\text { Festas, passeios, } \\
\text { brincar, jogar } \\
\text { e dançar }\end{array}$ & $\begin{array}{l}\text { "Brincadeira, jogos... quando nós fomo pro cinema com os menino daqui... } \\
\text { brincar, jogar, pular, tomar banho de piscina" (A1, } 10 \text { anos). }\end{array}$ \\
\hline & $\begin{array}{l}\text { Apoio das instituições } \\
\text { para familiares }\end{array}$ & $\begin{array}{l}\text { "É porque eu falei com aquela lá [profissional da instituição], ai eu falei } \\
\text { que... aí ela falou que ia ver pra ajudar minha família" (A2, } 12 \text { anos). }\end{array}$ \\
\hline & $\begin{array}{l}\text { Boa relação com } \\
\text { familiares, amigos, } \\
\text { parceiros românticos } \\
\text { e profissionais } \\
\text { das instituições }\end{array}$ & $\begin{array}{l}\text { "Quando eu tô com uma pessoa. Quando eu tô com uma pessoa quando } \\
\text { eu quero que ela esteja comigo... como o Renan [amigo] pra mim... eu fico } \\
\text { muito alegre. Quando tem alguma pessoa pra falar comigo, conversar as } \\
\text { coisas que acontece" (A4, } 16 \text { anos). }\end{array}$ \\
\hline \multicolumn{3}{|l|}{$\begin{array}{l}\text { Afeto } \\
\text { Negativo }\end{array}$} \\
\hline & $\begin{array}{l}\text { Punições por } \\
\text { desobedecer } \\
\text { a regras }\end{array}$ & $\begin{array}{l}\text { "Ficar indo pro quarto. Nós fica brincando demais na hora do almoço. } \\
\text { Aqui é diferente. Tem que se comportar, tem que obedecer ao educador, se } \\
\text { não obedecer vai pro quarto" (A1, } 10 \text { anos). }\end{array}$ \\
\hline & $\begin{array}{l}\text { Preconceito contra } \\
\text { a homossexualidade } \\
\text { e a situação de rua }\end{array}$ & $\begin{array}{l}\text { "Quando minha familia fala assim: "Ítalo, vai aprender a ser homem, ficar } \\
\text { com menina que é muito mais melhor do que ficar com homem". Aí eu } \\
\text { pego... não, mas eu vou ser do jeito que eu sou. Ai eu pego e saiu pra rua } \\
\text { de novo com raiva" (A4, } 16 \text { anos). }\end{array}$ \\
\hline & $\begin{array}{l}\text { Violência física, } \\
\text { sexual e emocional }\end{array}$ & $\begin{array}{l}\text { "Quando fica fazendo negócio de imoralidade com os menino. Às vezes } \\
\text { os menino toma banho lá fora, ai o cara fica querendo olhar a bunda do } \\
\text { outro. Tem gente que quer tomar banho, aí eles vão lá. Fica com negócio } \\
\text { que vai só pegar manga, vai pegar alguma coisa (A2, } 12 \text { anos). }\end{array}$ \\
\hline & $\begin{array}{l}\text { Realizar atividades } \\
\text { domésticas }\end{array}$ & $\begin{array}{l}\text { "Quando dá preguiça pra eu lavar minhas roupas. Quando eu olho pro } \\
\text { guarda-roupa assim que dá logo... arrepio logo" (A5, } 17 \text { anos). }\end{array}$ \\
\hline & Estar na rua & "Na rua. Ficava sozinho. Ficava pedindo" (A1, 10 anos). \\
\hline & $\begin{array}{l}\text { Conflitos com amigos, } \\
\text { familiares e profissio- } \\
\text { nais das instituições }\end{array}$ & $\begin{array}{l}\text { "Me sinto magoado às vezes quando a negada [amigos] não me chama, } \\
\text { porque toda vida que vou sair eu chamo, né? Fico naquela" (A6, } 17 \text { anos). }\end{array}$ \\
\hline
\end{tabular}

você se sentiu..." e "Em quais contextos [representados nas figuras] você se sentiu..."), o relacionamento com os pares e a presença dos familiares foram relacionados a emoções tanto positivas quanto negativas, a variar de acordo com circunstâncias prazerosas ou desprazerosas. Pesquisas sobre o bem-estar subjetivo têm verificado que relações com amigos e familiares são centrais para a compreensão desse construto (Gray, Chamratrithirong, Prasartkul, \& Prasart- 
kul, 2011; McAuley, McKeown, \& Merriman, 2012). Haja vista a especificidade dos jovens em situação de rua, os quais estiveram ou estão em instituições, os profissionais destas também estiveram presentes nas situações relacionadas aos afetos pesquisados.

Destaca-se que a particularidade dos jovens em situação de rua não estarem residindo na casa dos seus familiares e, portanto, tendo limitado tempo com a família de origem não se configura como fator determinante para elucidação de emoções negativas. Diferente disto compreende-se que essa população estabelece relações de apoio e afeto com seus pares e profissionais das instituições, além de manter contato, mesmo que esporádico, com suas famílias de origem (Morais, Paludo, \& Koller, 2010; Paludo \& Koller, 2008). Sendo assim, um reduzido tempo vivido com a família de origem não se constitui como a priori de afetos negativos. Em vista disto, ressalta-se que as relações significativas, afetivas e recíprocas em detrimento dos laços consanguíneos implicam no sentido de família dos indivíduos. Enfatiza-se, ainda, que o relacionamento familiar em detrimento de sua configuração possui maior expressividade sobre o bem-estar (Wagner, Ribeiro, Arteche, \& Bornholdt, 1999).

Quando questionados sobre como se sentem a maior parte do tempo, dentre os afetos investigados, quatro participantes referiram-se a afetos positivos (alegre) e dois apresentaram afetos negativos (irritado e triste). Observa-se que os afetos positivos foram relacionados ao lazer (atividades realizadas no tempo livre, como: passear e jogar), brincar (atividade lúdicas) e relacionamento com pares. $\mathrm{O}$ uso inadequado do tempo livre ("não ter nada pra fazer" - A6, 17 anos) e a insatisfação com condições atuais de vida foram relacionadas a afetos negativos. Conforme se verificou na literatura (Casas, González, \& Navarro 2014; Sarriera et al., 2013), estes resultados colaboram para a percepção de que as atividades esportivas e de lazer, envolvendo o uso apropriado do tempo livre e a interação com amigos e familiares estão relacionadas com o bem-estar subjetivo. Enfatiza-se que características pessoais de coping, otimismo, entre outras, podem influenciar o bem-estar, tal como visto nos estudos de bem-estar subjetivo relacionados às teorias da personalidade (Diener et al., 1999).

O participante (A5, 17 anos) relatou sentir-se triste ao dizer preferir estar com a família. Ressalta-se que o adolescente saiu de casa e não pode retornar por estar ameaçado de morte por um traficante de drogas. Além disso, compara a instituição atual com uma antiga, em que ele relatava se sentir em casa. $\mathrm{Na}$ atual, ele diz não receber apoio e incentivo dos profissionais e o espaço físico da instituição é descrito por ele como precário. Nesse sentido, nota-se que a escolha de como usar o tempo livre e as interações sociais envolvidas tendem a promover bem-estar. No entanto, as condições ambientais também podem ser fatores influentes. $\mathrm{O}$ ambiente e a participação dos jovens na ocupação desses espaços têm sido abordados em algumas pesquisas com objetivo de investigar o planejamento de ambientes e designs como indicadores de bem-estar (Casas et al., 2014). Dessa forma, faz-se relevante o investimento destinado a espaços apropriados para o lazer (praças e áreas esportivas, por exemplo) e tecnologias (computadores, internet, etc.).

Pontua-se que as atividades e interações descritas como preditores de emoções positivas para os jovens podem elevar seu potencial na promoção de bem-estar quando associadas ao monitoramento de pais ou responsáveis. Visto que, por exemplo, o relacionamento com amigos e algumas atividades escolhidas pelos jovens para serem usufruídas no tempo livre podem ser prejudiciais. Observa-se que o participante (A6, 17 anos) ao referir-se aos afetos positivos relacionou-os a situações em que estava com seus amigos, seja na rua ou em festas à noite, locais onde costuma conversar com amigos, ouvir música e consumir maconha e bebida alcoólica. Além disso, o laço de amizade estabelecido por ele e seus pares envolve brigas, entre outros atos infracionais. A relação com familiares também precisa ser relativizada ao passo que a violência intrafamiliar e a negligência estão presentes no contexto familiar, inclusive de alguns dos participantes desse estudo, tal como relata o participante (A1, 10 anos) sobre o afeto magoado: " $E m$ casa. Minha mãe me batia". 
Este estudo segue em acordo com as pesquisas na área do Desenvolvimento Humano e da Psicologia Positiva que compreendem as pessoas numa perspectiva sistêmica e integrativa, na qual se considera os riscos e fatores prejudiciais e enfatiza os aspectos positivos e de proteção. Ambos não são excludentes, mas considerados em relação. Dessa forma, torna-se possível perceber as ambiguidades presentes nos relatos dos participantes, que ora apresentam, por exemplo, a família relacionada a afetos positivos e ora apresenta-a relacionada a afetos negativos. $\mathrm{O}$ mesmo participante (A1, 10 anos) mencionado acima, diz sentir saudades da mãe e que se sentiu feliz quando ela o levou para tomar banho de mar.

No presente estudo, a rua e a família foram os contextos mais associados aos afetos negativos quando comparados à instituição, a escola e os amigos. Porém, os afetos positivos não estiveram excluídos da rua e da família. Assim como, podem-se observar os afetos negativos nos demais contextos. Como explicitado anteriormente, em fundamento, o bem-estar subjetivo é descrito por avaliações subjetivas acerca das experiências de vida. Dessa forma, os resultados das entrevistas desta pesquisa tendem a verificar que o contexto não é definidor isolado das experiências que envolvem os afetos positivos e/ou negativos. As situações e contextos analisados variam nas avaliações dos entrevistados ao relacioná-los aos afetos investigados, apresentando que tanto os afetos positivos quanto os negativos podem decorrer de experiências ocorridas num mesmo contexto, por exemplo, a família.

A análise das falas dos participantes acerca do bem-estar subjetivo contribuiu para uma compreensão complexa e sistêmica que supera a relação linear (de causa e efeito) dos indicadores relacionados ao bem-estar. Nesse sentido, a afirmação de que as relações familiares e com amigos, entre outras atividades e interações, são preditores de bem-estar precisam ser contextualizadas. De forma que seja possível a compreensão de falas que denunciam familiares e profissionais das instituições como violadores de direitos e relacionados a afetos negativos, mas que também o percebem como potenciais de proteção e relacionados a afetos positivos, a depender da história de vida de cada adolescente. Assim, acentua-se a função da rede social que pode favorecer emoções positivas, na medida em que, por exemplo, o espaço comunitário pode propiciar espaços de lazer (quadras, praças, etc.), assim como, a estrutura e profissionais das instituições podem atuar como fonte de apoio para os adolescentes.

\section{Considerações Finais}

Este artigo buscou compreender o significado de bem-estar subjetivo para crianças e adolescentes em situação de rua a partir da realização de estudos de casos múltiplos. Esta estratégia de pesquisa permitiu a análise cruzada das situações e comportamentos de seis jovens em situação de rua. Dessa forma, foi possível acessar o sentido de bem-estar subjetivo para os participantes, identificando as situações, as pessoas e os contextos envolvidos no que se refere aos afetos investigados, assim como os fatores relacionados à satisfação de vida.

Os participantes deste estudo foram encontrados em diferentes locais (instituições, serviço aberto e rua) para a realização das entrevistas, o que possibilitou uma investigação ampliada da avaliação do bem-estar subjetivo. Os instrumentos utilizados mostraram-se adequados, mesmo para serem aplicados na rua. Em alguns locais foi possível apresentar todas as figuras e fichas ao mesmo tempo. Em outros, visto as condições ambientais (praça pública, por exemplo) foi investigada cada figura em separado. Porém, anteriormente, foi explicitada a existência de todos os cinco contextos assim como das fichas relativas aos afetos, buscando minimizar as diferenças na aplicação dos instrumentos entre os ambientes de pesquisa.

O uso de figuras facilitou a exposição dos conteúdos relacionados aos afetos investigados. A visualização dos contextos em figuras e fichas nomeando os afetos tornou o momento de coleta de dados lúdico e dinâmico. Além disso, os adolescentes foram instruídos a escolherem de acordo com a preferência os afetos que iriam abordar. Esta livre escolha e o manuseio dos objetos 
envolveram os adolescentes numa participação ativa, diminuindo possibilidades de cansaço e desinteresse durante a entrevista. Da mesma forma avalia-se o uso do desenho para acessar conteúdos relativos à satisfação de vida. Nota-se que a utilização de estratégias metodológicas que abordem o conteúdo no contexto de forma lúdica e experiencial é favorável à obtenção da validade de pesquisas com crianças e adolescentes em situação de rua. Em relação à postura do(a) pesquisador(a), ressalta-se que a pesquisa com essa população exige criatividade, tanto no que se refere à aplicação de instrumentos quanto à adequação das metodologias aos diferentes contextos, redefinindo e reajustando métodos ao visar, em primazia, o bem-estar dos participantes.

Nas entrevistas verificou-se que os afetos positivos envolveram momentos em que os participantes estavam à vontade, se relacionando e engajados em atividades, em interação com as pessoas e o meio de forma a potencializar os atributos desenvolvimentais. Ou seja, foram situações positivas promotoras de desenvolvimento, que proporcionaram o exercício das características geradoras, de competência e demanda, tal como abordam Bronfenbrenner e Morris (2006).

Este estudo verificou que os fatores externos não são determinantes, numa relação linear de causalidade, do bem-estar subjetivo. Cada indivíduo percebe o bem-estar subjetivo em sua idiossincrasia. Ou seja, os eventos adversos como a violência física, sexual e emocional são potencialmente prejudiciais ao desenvolvimento e ao bem-estar dos participantes. Entretanto, estas não são consideradas isoladas. Enfatiza-se a existência de outras variáveis que podem atuar neutralizando ou minimizando os possíveis prejuízos.

Algumas relações estabelecidas com as pessoas e os contextos evidenciaram a negligência, violência, entre outras adversidades que podem influenciar negativamente o bem-estar subjetivo. Por isto, a necessidade de contextualizar a rede de apoio antes de constatá-la exclusivamente como proteção. Destarte, as experiências agradáveis na rede de apoio podem ser favoráveis ao bem-estar, visto que a vivência de eventos nega- tivos de vida não excluíram a expressão de afetos positivos e satisfação de vida.

Este estudo descreveu crianças e adolescentes em situação de rua que se auto referem como amorosos, felizes e satisfeitos com suas vidas. Evidenciou, ainda, a existência de situações de violência, uso de drogas, etc., mas elucidando que isto não os limita a viverem tristes, deprimidos e abandonados. Estas características negativas podem representar um estereótipo pertencente ao imaginário social, o que dificulta a população em geral compreender os jovens em situação de rua em suas emoções positivas e satisfeitos com suas vidas, apesar das adversidades. Desnaturaliza-se, portanto, a situação de rua, assim como as características pejorativas e estereotipadas a ela relacionadas, ressaltando-se a perspectiva dessa população como autores de suas vidas e que, com o auxílio de uma rede de apoio protetiva, podem superar a situação de vulnerabilidade e dos riscos enfrentados na vida cotidiana.

\section{Referências}

Bardin, L. (1979). Análise de conteúdo (L. Reto \& A. Pinheiro, Trads.). São Paulo, SP: Edições 70. (Original publicado em 1977)

Bronfenbrenner, U. (1996). A ecologia do desenvolvimento humano: Experimentos naturais e planejados. Porto Alegre, RS: Artes Médicas. (Original publicado em 1979)

Bronfenbrenner, U. (2011). Bioecologia do desenvolvimento humano: Tornando os seres humanos mais humanos. Porto Alegre, RS: Artmed.

Bronfenbrenner, U., \& Morris, P. A. (2006). The bioecological model of human development. In W. Damon \& R. M. Lerner (Eds.), Handbook of child psychology: Vol. 1. Theoretical models of human development ( $6^{\text {th }}$ ed., pp. 793-828). New York: John Wiley.

Casas, F., González, M., \& Navarro, D. (2014). Social psychology and child well-being. In A. Ben-Arieh, F. Casas, I. Frones, \& J. E. Korbin (Eds.), Handbook of child well-being: Theories, methods and policies in global perspective (Vol. 1, pp. 513-554). New York: Springer.

Cecconello, A. M., \& Koller, S. H. (2003). Inserção ecológica na comunidade: Uma proposta meto- 
dológica para o estudo de famílias em situação de risco. Psicologia: Reflexão e Crítica, 16(3), 515524. doi:10.1590/S0102-79722003000300010

Conselho Federal de Psicologia. (2000). Resolução para pesquisas com seres humanos. Resolução 016/2000. Brasília, DF: Autor.

Conselho Nacional de Saúde. (1996). Resolução $n^{o}$ 196, de 10 de outubro de 1996. Diretrizes e normas regulamentadoras de pesquisa envolvendo seres humanos. Brasília, DF: Autor.

Damásio, B. F., Pacico, J. C., Poletto, M., \& Koller, S. H. (2013). Refinement and psychometric properties of the eight-item Brazilian Positive and Negative Affective Schedule for Children (PANAS-C8). Journal of Happiness Studies, 14(4), 1363-1378. doi:10.1007/s10902-0129383-x

Diener, E. (2012). New findings and future directions for subjective well-being research. The American Psychologist, 67(8), 590-597. doi:10.1037/ a0029541

Diener, E., Emmons, R. A., Larsen, R. J., \& Griffin, S. (1985). The satisfaction with life scale. Journal of Personality Assessment, 49(1), 71-75. doi:10.1207/s15327752jpa4901_13

Diener, E. D., Suh, E. M., Lucas, R. E., \& Smith, H. L. (1999). Subjetive well-being: Three decades of progress. Psychological Bulletin, 125(2), 276-302. doi:10.1037/0033-2909.125.2.276

Eschiletti-Prati, L., Paula Couto, M. C. De, Moura, A. da S., Poletto, M., \& Koller, S. H. (2008). Revisitando a inserção ecológica: Uma proposta de sistematização. Psicologia: Reflexão e Crítica, 21, 160-169. doi:10.1590/S010279722008000100020

Estatuto da Criança e do Adolescente. (1990, 16 jul.). Lei 8.069. de 13 de julho de 1990. Dispõe sobre o Estatuto da Criança e do Adolescente e dá outras providências. Diário Oficial da União.

Gehring, T. M. (1993). Family System Test (FAST). Göttingen, Germany: Hogrefe \& Huber.

Giacomoni, C. H. (2004). Bem-estar subjetivo: Em busca da qualidade de vida. Temas em Psicologia, 12(1), 43-50. Recuperado em http://pepsic. bvsalud.org/pdf/tp/v12n1/v12n1a05.pdf

Giacomoni, C. H., \& Hutz, C. S. (2006). Escala de Afeto Positivo e Negativo para crianças: Estudo de construção e validação. Revista Semestral da Associação Brasileira de Psicologia Escolar e Educacional (ABRAPEE), 10(2), 235-245. Recuperado em http://www.scielo.br/pdf/pee/ v10n2/v10n2a06.pdf

Gomes, M. A., \& Pereira, M. L. D. (2005). Família em situação de vulnerabilidade social: Uma questão de políticas públicas. Ciência \& Saúde Coletiva, 10(2), 357-363. Recuperado em http:// www.scielo.br/pdf/csc/v10n2/a13v10n2.pdf

Gray, R. S., Chamratrithirong, A. P., Prasartkul, U., \& Prasartkul, P. (2011). Happiness among adolescent students in Thailand: Family and non-family factors. Social Indicators Research, 110(2), 703719. doi:10.1007/s11205-011-9954-y

Koller, S. H., \& Hutz, C. (1996). Meninos e meninas em situação de rua: Dinâmica, diversidade e definição. Coletâneas da ANPEPP: Aplicações da Psicologia na Melhoria da Qualidade de Vida, 1, 11-34. Recuperado em https://www.infocien. org/Interface/Colets/v1n12a02.pdf

Lima, R. F. F. (2014). Bem-estar subjetivo de crianças e adolescentes em situação de rua (Dissertação de mestrado, Programa de Pós-Graduação em Psicologia, Universidade de Fortaleza, Fortaleza, CE, Brasil).

McAuley, C., McKeown, C., \& Merriman, B. (2012). Spending time with family and friends: Children's views on relationships and shared activities. Child Indicators Research, 5(3), 449-467. doi:10.1007/s12187-012-9158-2

Morais, N. A. (2009). Trajetórias de vida de crianças e adolescentes em situação de vulnerabilidade social: Entre o risco e a proteção (Tese de doutorado). Recuperado em http://hdl.handle. net $/ 10183 / 16660$

Morais, N. A., Koller, S. K, \& Raffaelli, M. (2010). Eventos estressores e indicadores de ajustamento entre adolescentes em situação de vulnerabilidade social no Brasil. Universitas Psychologica, 9(3), 315-330. Recuperado em http://www.scielo.org.co/scielo.php?script=sci_ arttext\&pid $=$ S1657-92672010000300015\&lng= en\&tlng $=\mathrm{pt}$

Morais, N. A., Koller, S. H., \& Raffaelli, M. (no prelo). Inserção ecológica na pesquisa sobre trajetórias de vida de adolescentes em situação de vulnerabilidade social: Identificando fatores de risco e proteção. In S. S. Paludo \& S. H. Koller (Eds.), Inserção ecológica: Um método de estudo do desenvolvimento humano. São Paulo, SP: Casa do Psicólogo. 
Morais, N. A., Paludo, S., \& Koller, S. H. (2010). Famílias de crianças e adolescentes em situação de rua. In N. A. Morais, L. Neiva-Silva, \& S. H. Koller (Eds.), Endereço desconhecido: Crianças e adolescentes em situação de rua (pp. 177197). São Paulo, SP: Casa do Psicólogo.

Paludo, S., \& Koller, S. H. (2008). Toda criança tem família: Criança em situação de rua também. Psicologia \& Sociedade, 20(1), 42-52. Recuperado em http://hdl.handle.net/10183/20679

Poletto, M. (2011). Bem-estar subjetivo: Um estudo longitudinal com crianças e adolescentes em situação de vulnerabilidade social (Tese de doutorado). Recuperado em http://hdl.handle. net $/ 10183 / 31938$

Raffaelli, M., Morais, N. A., \& Koller, S. H. (2013). Children at risk: The case of Latin American street youth. In A. Ben-Arieh; F. Casas, \& J. Korbin (Eds.), Handbook of child well-being: Theories, methods and policies in global perspective (pp. 2653-2668). Dordrecht, Germany: Springer.

Sarriera, J. C., Paradiso, A. C., Abs, D., Soares, D. H. P., Silva, C. L., \& Fiuza, P. J. (2013). O bem-estar pessoal dos adolescentes através do seu tempo livre. Estudos de Psicologia (Natal), 18(2), 285295. doi:10.1590/S1413-294X2013000200014

Siqueira, A. C., \& Dell'Aglio, D. D. (2010). Crianças e adolescentes institucionalizados: Desempenho escolar, satisfação de vida e rede de apoio social. Psicologia: Teoria e Pesquisa, 26(3), 407-415. doi:10.1590/S0102-37722010000300003
Snyder, C. R., \& Lopez, S. J. (2009). Psicologia Positiva: Uma abordagem cientifica e prática das qualidades humanas. Porto Alegre, RS: Artmed.

Wagner, A., Ribeiro, L. de S., Arteche, A. X., \& Bornholdt, E. A. (1999). Configuração familiar e o bem-estar psicológico dos adolescentes. Psicologia: Reflexão e Crítica, 12(1), 147156. doi:10.1590/S0102-79721999000100010

Watson, D., Clark, L. A., \& Tellegen, A. (1988). Development and validation of brief measures of Positive and Negative Affect: The PANAS Scales. Journal of Personality and Social Psychology, 54(1), 1063-1070. doi:10.1037/00223514.54.6.1063

Yin, R. K. (2010). Estudo de caso: Planejamento e métodos. Porto Alegre, RS: Bookman.

Yunes, M. A. M., Arrieche, M. R. de O., Tavares, M. de F. A., \& Faria, L. C. (2001). Família vivida e família pensada na percepção de crianças em situação de rua. Paidéia (Ribeirão Preto), 11(20), 47-56. doi:10.1590/S0103-863X2001000200006
Recebido: 25/09/2014

$1^{a}$ revisão: 22/12/2014 Aceite final: 12/01/2015 